\title{
Endodontic Management of Pathologic Root Resorption using EndoSeal Mineral Trioxide Aggregate
}

\author{
${ }^{1}$ Shefali Wadhwani, ${ }^{2}$ Mahesh P Singh, ${ }^{3}$ Manish Agarwal, ${ }^{4}$ Santosh K Singh
}

\begin{abstract}
Mineral trioxide aggregate (MTA) has emerged as a reliable bioactive material with extended applications in endodontics that includes the obturation of the root canal space. Recently, introduced sealers based on MTA have been reported to be biocompatible, also to stimulate mineralization and encourage apatite-like crystalline deposits along the apical and middle third of the canal walls. This article examines the literature supporting EndoSeal MTA (MARUCHI, Wonju, Korea) as a root canal sealer, suggests method for its delivery and placement, and presents a case report that demonstrates its effectiveness in resolving a chronic periapical lesion.
\end{abstract}

Keywords: EndoSeal mineral trioxide aggregate, Pathologic root resorption, Sealer.

How to cite this article: Wadhwani S, Singh MP, Agarwal M, Singh SK. Endodontic Management of Pathologic Root Resorption using EndoSeal Mineral Trioxide Aggregate. Int J Prosthodont Restor Dent 2017;7(1):34-37.

Source of support: Nil

Conflict of interest: None

\section{INTRODUCTION}

Endodontic treatment is aimed at eliminating infection source creating a fluid-tight seal of the root canal system. ${ }^{1}$ Endodontic sealers are used for the obturation of root canal systems in order to achieve a fluid-tight seal between the dentinal wall and core-filling material throughout the entire canal. ${ }^{2}$

Commercially available various sealers are categorized according to chemical components: Zinc-oxide eugenol, calcium hydroxide-containing, resin-based, glassionomer-based, silicone-based, and newer generation bioceramic-based sealers. ${ }^{3}$

As root canal sealers are placed in close contact with the surrounding soft and hard tissues for a long period

\footnotetext{
${ }^{1}$ Postgraduate Student, ${ }^{2}$ Professor and Head, ${ }^{3}$ Professor ${ }^{4}$ Reader

${ }^{1-4}$ Department of Conservative Dentistry and Endodontics People's College of Dental Sciences and Research Centre Bhopal, Madhya Pradesh, India

Corresponding Author: Shefali Wadhwani, Postgraduate Student, Department of Conservative Dentistry and Endodontics People's College of Dental Sciences and Research Centre Bhopal, Madhya Pradesh, India, Phone: +919713843537 e-mail: shef13h14@gmail.com
}

of time, they should have good biocompatibility and should be well tolerated by the periradicular tissues. At present, none of the endodontic sealers satisfy all the ideal properties as stated by Grossman, ${ }^{4}$ hence, new sealers are constantly being developed.

Mineral trioxide aggregate (MTA - Angelus, Londrina, Brazil) after its introduction in 1993 is widely used in apical barrier formation, pulp capping, pulpotomy, and sealing-perforated dental roots with an open apex. However, the difficult handling makes it complicated to fill a narrow root canal with the material. It is also difficult to remove MTA after it hardens, which makes retreatment difficult. These characteristics have limited the use of MTA as a direct filling material within the root canal..$^{5}$ Recently, bioceramic-based materials, such as EndoSequence BC Sealer (Brasseler USA, Savannah, GA), EndoSeal MTA (MARUCHI, Wonju, Korea), and MTA Fillapex (Angelus Soluc, õesOdontológicas, Londrina, PR, Brazil) have received considerable attention because of their favorable physicobiological properties. Among them, EndoSequence BC Sealer and EndoSeal MTA are supplied in a premixed injectable paste and thus give clinicians easy manipulation. ${ }^{6}$

EndoSeal (Maruchi, Korea) is a premixed and injectable endodontic sealer that uses moisture in the air to initiate the setting reaction. A recent study indicates that EndoSeal has comparable physical properties to MTA and superior biocompatibility compared with AH Plus (Dentsply) resin-based sealers. ${ }^{7}$

However, not many clinical cases have been reported with regard to the use of this material as endodontic sealer; therefore, this article presents endodontic management of a pathologic root resorption case using EndoSeal MTA-based sealer (MARUCHI, Korea).

\section{CASE REPORT}

A 25-year-old female patient was referred to the Department of Conservative Dentistry and Endodontics with a grossly carious molar in the lower right back tooth region. The patient gave history of pain only on mastication along with history of visiting a private dentist for endodontic therapy, which was not completed. On clinical examination, it was found that right mandibular first molar (\#46) had deep carious lesion with fractured distolingual cusp and presented tenderness on percussion. Patient's 


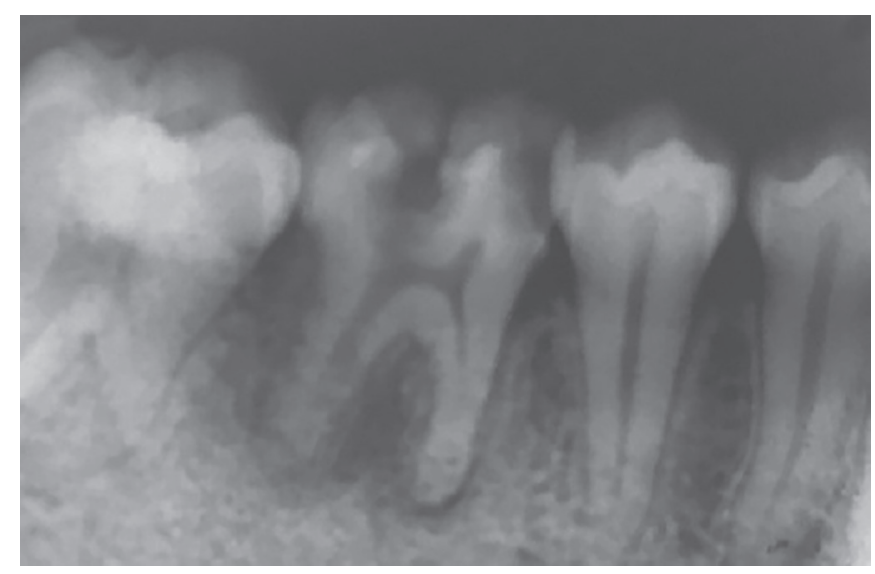

Fig. 1: Preoperative intraoral periapical radiograph

intraoral periapical radiograph showed evidence of periapical radiolucency as well as distal root resorption suggestive of a long-standing chronic periapical lesion (Fig. 1).

A provisional diagnosis of chronic periapical lesion with pathologic root resorption was made, and the patient was explained about the bone loss and prognosis of that tooth. Consent of the patient was taken and endodontic therapy of the right mandibular first molar after oral prophylaxis was planned.

A modified access was done for the tooth under rubber dam isolation using split dam technique. Three canals [mesiobuccal (MB), mesiolingual (ML), and distal] were located and enlarged using rotary Sx file (Dentsply Maillefer, Ballaigues, Switzerland). Continuous pus discharge was seen from the canals following copious irrigation with normal saline. Cleaning and shaping was performed up to a file size of $20 \mathrm{~K}$ file (MANI) after establishing the working length using, Ingle's method ${ }^{8}$ of working length determination (Fig. 2).

The access cavity was left open to allow the discharge to abate and the patient was recalled the next day for further procedure. In the next visit, the canals after irrigation with normal saline were dried using paper points and working length was confirmed using electronic apex locator (Canal Pro; Coltene, Whaledent). All the canals were prepared using crown-down technique using rotary files (ProTaper Universal; Dentsply Maillefer) with $17 \%$ ethylenediaminetetraacetic acid (EDTA) (Glyde; Dentsply Ballaigues, Switzerland). MB and ML canals were prepared till F1 (Universal ProTaper) whereas distal canal was prepared till F2 (Universal ProTaper). Copious irrigation was done with $5.25 \%$ sodium hypochlorite alternating with $17 \%$ EDTA solution to finish the irrigation protocol. Plain normal saline was used to neutralize any active irrigant followed by drying using paper points. Combination of calcium hydroxide and $2 \%$ chlorhexidine ( $\mathrm{CHX}$ ) was used as intracanal medicament for a period of 7 days. Similarly, the dressing was repeated for another period of 7 days.

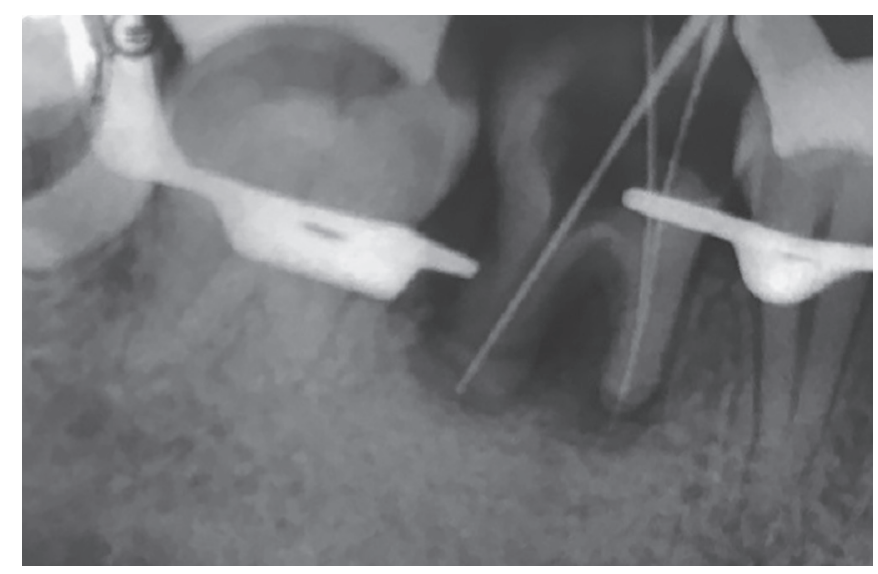

Fig. 2: Working length radiograph

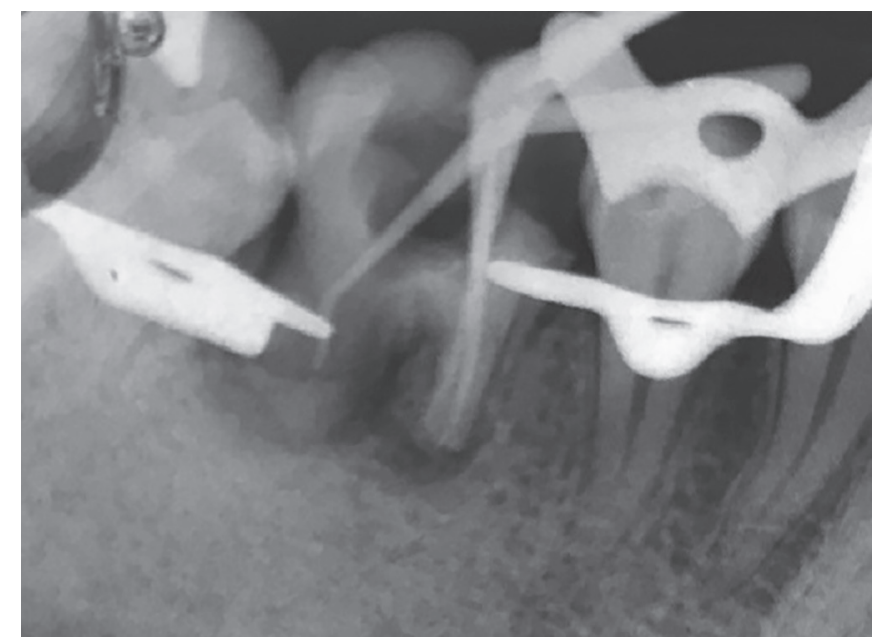

Fig. 3: Master cone radiograph

On the subsequent visit, the patient was asymptomatic. The intracanal medicament was removed with repeated saline irrigation and ultrasonic activation (Micro Mega Endo Sonic Air MM1500); 17\% EDTA solution was used to remove the smear layer followed by a final flush with $2 \% \mathrm{CHX}$ and the canals were dried using paper points. Appropriate size master gutta-percha cones were selected and confirmed using a master cone intraoral periapical radiograph (Fig. 3).

As per the manufacturer's instructions, using a 23-gauge needle, the EndoSeal MTA was injected until it tightly filed the root apex. Then, respective size guttapercha cone was inserted and pumped lightly. Excess gutta-percha was removed with a heat carrier and the remaining gutta-percha was vertically compacted into the root canals to ensure a three-dimensional obturation of the canal system without any voids and a permanent coronal seal using composite restoration was done (Fig. 4). Patient was recalled after 3 months as well as after 6 months for the follow-up to assess the periapical healing followed by tooth preparation for crown (Fig. 5). 


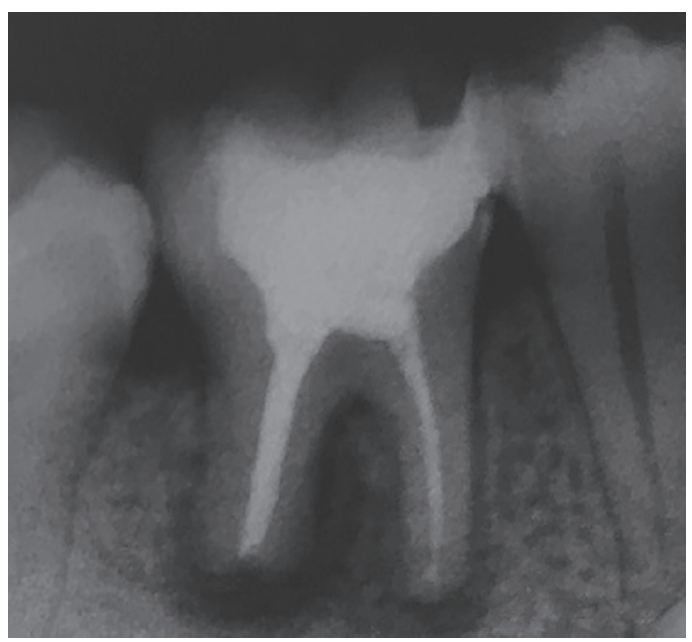

Fig. 4: Postobturation radiograph

\section{DISCUSSION}

The obturation of the prepared radicular space has been achieved by using a wide variety of core materials that have been classified as cements, pastes, plastics, or solids. Gutta-percha, in its various forms, has remained the paragon as a root canal filling material during the course of the last century. The development of core materials and delivery techniques has generated carrier-based gutta-percha and resin-based systems. These filling materials are combined with sealers to provide an adequate obturation of the root canal space that ideally prevents the emergence of endodontic disease and encourages periapical healing.

The materials that can be used to fill the root canal space should exhibit certain characteristics that allow for predictable placement and prevent and resolve endodontic disease. A current trend in endodontic research is to explore various alternatives to gutta-percha to identify suitable filling materials that can provide greater resistance against coronal and apical microleakage and thus protection from bacterial contamination. ${ }^{9}$

As root canal sealers are placed in close contact with the surrounding soft and hard tissues for long periods of time, there is always a possibility of the sealers gaining access to the periradicular tissues via dentinal tubules, lateral and accessory canals, or apical foramina. Although sealers should be confined within the root canal, their inadvertent extrusion beyond the apical foramina into the periradicular tissues may occur. Thus, toxic components of sealers, particularly in case of open apex due to iatrogenic overinstrumentation, pathologic root resorption, nonvital teeth with immature roots, would damage both the periodontal ligament and the alveolar bone, adversely affecting the treatment outcome. Therefore, the sealers should have good biocompatibility and should be well tolerated by the periradicular tissues. At present, none

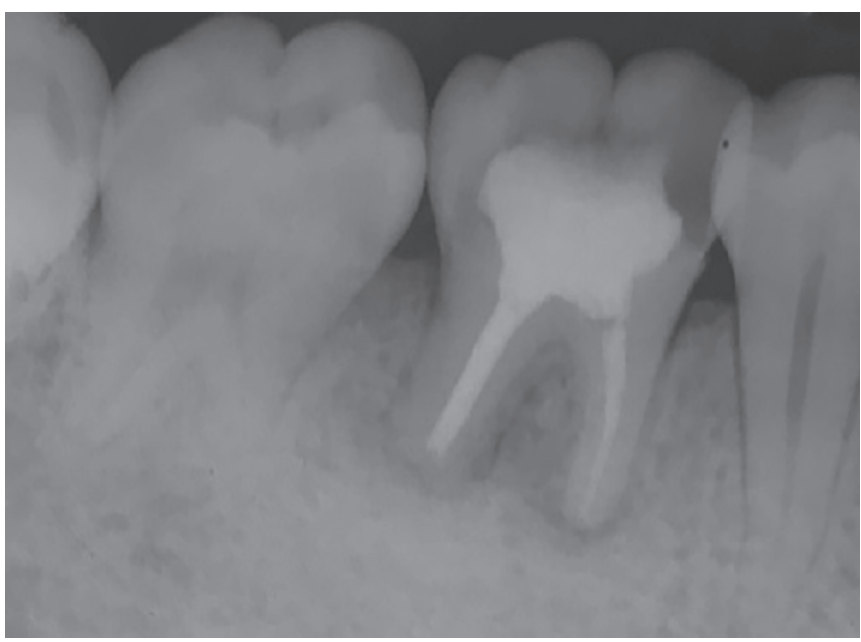

Fig. 5: Six months follow-up radiograph

of the endodontic sealers satisfy all the ideal properties as stated by Grossman; hence, new sealers are constantly being developed. ${ }^{10}$

Taking into consideration many factors affecting dentinal tubule penetration by a sealer, MTA might have a profound advantage when used as canal obturation material because of its superior physiochemical and bioactive properties. The original material (Pro-Root MTA; Dentsply Tulsa Dental, Tulsa, OK) was introduced to seal all pathways of communication and as a root-end filling material in endodontic surgery. ${ }^{9}$ However, MTA cannot be recommended as a routine orthograde root canal filling material because the sandy property and irretrievability of the substance ${ }^{9}$ have made it challenging to be used in a complicated root canal system.

EndoSeal MTA (Maruchi, Wonju, Korea), a finely pulverized pozzolan-based MTA, was recently introduced. The pozzolan cement, the main component of this sealer, gets cementitious properties after pozzolanic reaction that includes calcium hydroxide and water, and enables sufficient flow of the premixed substrate though injection tip with adequate working consistency. The favorable mechanical characteristics, such as fast setting time (around 4 minutes), higher washout resistance than other commercially available MTAs, and biologic effects including biocompatibility, mineralization potential, and odontogenic effect of the pozzolan cement had been previously reported. ${ }^{1}$

According to a study by Kim and $\mathrm{Shin}^{10}$ on cytotoxicity of MTA-based root canal sealer in 2014, these sealers have been reported to be biocompatible and stimulate mineralization, and also encourage apatite-like crystalline deposits along the apical and middle third of the canal walls. ${ }^{6}$

Another study done by Lim et $\mathrm{al}^{2}$ on physical properties and biocompatibility of this injectable calcium silicatebased root canal sealer in 2015 stated several biological 
advantages of the high $\mathrm{pH}$ of the root canal sealers. Firstly, high $\mathrm{pH}$ of the sealer can promote hard tissue formation, such as apical obliteration with calcified tissue. Second, high sealer alkalinity changes the environment in the dentin to a more alkaline $\mathrm{pH}$, possibly interfering with osteoclastic activity and promoting alkalinization in the adjacent tissues, which favors healing. Therefore, the high $\mathrm{pH}$ of EndoSeal may exert an advantageous effect compared with conventional resin-based sealers.

Also, property of flow allows a sealer to penetrate into the irregularities and accessory canals of the root canal system. In the aforementioned study by Lim et al, ${ }^{2}$ EndoSeal containing small particles of calcium silicate showed significantly higher flow values compared with the resin-based sealers. However, if the flow is excessive, the risk of sealer extrusion beyond apical foramen is increased, which could damage periodontal tissues or important anatomical structures, such as inferior alveolar nerve or maxillary sinus. Because EndoSeal is an injectable material which is susceptible to be extruded, this should be used along with gutta-percha for obturation.

Regardless of the composition, most of the currently used sealer systems consist of a powder/liquid or base/ catalyst, and these two components must be mixed at chairside and then applied to the root canal coated with gutta-percha. During this procedure, the sealer may contaminate the pulp chamber and any remaining sealer may induce tooth discoloration. According to a study by Lee et $\mathrm{al}^{7}$ on tooth discoloration in 2016, a novel MTAbased root canal sealer, EndoSeal showed discoloration, i.e., comparable with that of AH Plus and significantly lower than ProRoot which was found to be within an acceptable limit.

\section{CONCLUSION}

Collectively, very few studies done on EndoSeal MTA indicate that it has comparable physical properties to
MTA, favorable biocompatibility/odontogenicity compared with AH Plus, a widely used resin-based sealer, decrease in its cytotoxicity with time unlike other sealers, and because of its injection type dentist-friendly application, it is a self-sealing root canal sealer.

Also, in conjunction with well fit gutta-percha cone and vertical pressure, the sealer resulted in consistent dentinal tubule biomineralization. Therefore, EndoSeal MTA has the potential to be used as a predictable root canal sealer.

\section{REFERENCES}

1. Yoo YJ, Baek SH, Kum KY, Shon WJ, Woo KM, Lee W. Dynamic intratubular biomineralization following root canal obturation with pozzolan-based mineral trioxide aggregate sealer cement. Scanning 2016 Jan-Feb;38(1):50-56.

2. Lim E-S, Park Y-B, Kwon Y-S, Shon W-J, Lee K-W, Min K-S. Physical properties and biocompatibility of an injectable calcium-silicate-based root canal sealer: in vitro and in vivo study. BMC Oral Health 2015 Oct;15:129.

3. Cohen S, Hargreaves KM. Cohen's pathways of the pulp. 10th ed. Mosby: Elsevier India Pvt. Ltd, 2011.

4. Grossman, L. Obturation of root canal. In: Grossman L, editor. Endodontic practice. 10th ed. Philadelphia (PA): Lea and Febiger; 1982. p. 297.

5. Kim H, Kim Y, Nam S, Taeyub K, Kim H. Evaluation of sealing effect and working time of root canal filling MTA materials. J Korean Acad Pediatr Dent 2016 May;43(2):129-136.

6. Lee KJ, Kwak SW, Ha JH, Lee WC, Kim HC. Physicochemical properties of epoxy resin-based and bioceramic-based root canal sealers. Bioinorg Chem Appl 2017 Jan;2017:8.

7. Lee DS, Lim MJ, Choi Y, Rosa V, Hong CU, Min KS. Tooth discoloration induced by a novel mineral trioxide aggregate based root canal sealer. Eur J Dent 2016 Jul-Sep;10(3):403-407.

8. Ingle JI, Bakland LK, Baumgartner JC. Ingle's endodontics. 6th ed. Hamilton (ON): BC Decker; 2008.

9. Bogen $\mathrm{G}$, Kuttler S. Mineral trioxide aggregate obturation: a review and case series. J Endod 2009 Jun;35(6):777-790.

10. Kim RY, Shin JH. Cytotoxicity of a novel mineral trioxide aggregated-based root canal sealer. Dent Mater J 2014 Feb;33(3):313-318. 